Article

\title{
Comparison of Artificial Neural Networks and Response Surface Methodology towards an Efficient Ultrasound-Assisted Extraction of Chlorogenic Acid from Lonicera japonica
}

\author{
Hui-Chuan Yu ${ }^{1}$, Shang-Ming Huang ${ }^{1}$, Wei-Min Lin ${ }^{2}$, Chia-Hung Kuo ${ }^{3, *(1)}$ and \\ Chwen-Jen Shieh ${ }^{1, *}$ \\ 1 Biotechnology Center, National Chung Hsing University, 250 Kuokuang Road, Taichung 40227, Taiwan; \\ cathy_yu55@hotmail.com (H.-C.Y.); zxzxmj2323@hotmail.com (S.-M.H.) \\ 2 Department of Chemical Engineering, National Chung Hsing University, 145 Xingda Road, Taichung 40227, \\ Taiwan; lin78115@hotmail.com \\ 3 Department of Seafood Science, National Kaohsiung University of Science and Technology, \\ 142 Haijhuan Road, Nanzih District, Kaohsiung 811, Taiwan \\ * Correspondence: kuoch@nkust.edu.tw (C.-H.K.); cjshieh@nchu.edu.tw (C.-J.S.); \\ Tel.: +886+7+361-7141 (ext. 23646) (C.-H.K.); +886+4+2284-0450 (ext. 5121) (C.-J.S.)
}

Academic Editors: Maria Lisa Clodoveo and Filomena Corbo Received: 17 May 2019; Accepted: 20 June 2019; Published: 21 June 2019

check for updates

\begin{abstract}
Chlorogenic acid (CGA), a bioactive compound commonly found in plants, has been demonstrated possessing nutraceutical potential in recent years. However, the more critical issue concerning how to improve production efficacy of CGA is still limited. It is a challenge to harvest a large amount of CGA without prolonging extraction time. In this study, the feasibility of using ultrasound for CGA extraction from Lonicera japonica was investigated. A central composite design (CCD) was employed to evaluate the effects of the operation parameters, including temperature, ethanol concentration, liquid to solid ratio, and ultrasound power on CGA yields. Meanwhile, the process of ultrasound-assisted extraction was optimized through modeling response surface methodology (RSM) and artificial neural network (ANN). The data indicated that CGA was efficiently extracted from the flower of Lonicera japonica by ultrasound assistance. The optimal conditions for the maximum extraction of CGA were as follows: The temperature at $33.56{ }^{\circ} \mathrm{C}$, ethanol concentration at $65.88 \%, \mathrm{~L} / \mathrm{S}$ ratio at $46: 1 \mathrm{~mL} / \mathrm{g}$ and ultrasound power at $150 \mathrm{~W}$. ANN possessed greater optimization capacity than RSM for fitting experimental data and predicting the extraction process to obtain a maximum CGA yield. In conclusion, the process of ultrasound-assisted extraction can be well established by a methodological approach using either RSM or ANN, but it is worth mentioning that the ANN model used here showed the superiority over RSM for predicting and optimizing.
\end{abstract}

Keywords: Lonicera japonica; chlorogenic acid; extraction; optimization; response surface methodology; artificial neural networks

\section{Introduction}

Phenolic acids have received a great deal of attention over the years due to its beneficial biological activities. CGA is a common phenolic acid abundantly found in the coffee-related natural products, vegetables, and fruits [1]. Structurally, CGA is a family of esters formed between caffeic acid and quinic acids. Neochlorogenic acid (5-O-caffeoylquinic acid) is a very common isomer in CGA. It has been widely demonstrated that CGA shows diverse bioactivities and health-promoting functionality such as hepatoprotective, cardioprotective, anti-inflammation, antioxidant, anti-cancer, and anti-bacteria [2]. 
However, literature has indicated that the high-temperature water extraction process can lead to CGA isomerization, transformation and degradation [3], consequently reducing the antioxidant activity [4,5] and other biological activity [3] of CGA.

The conventional extraction method of CGA, e.g., the Soxhlet extraction method or flask-shaking method is time-consuming, generally exhibits low production efficiency [5] and low reproducibility [3]. Moreover, the extraction process requires large amounts of solvent and continuous heating at a high temperature. In order to improve the yield and the quality of final products, the use of ultrasound for bioactive compound extraction is a feasible approach to achieve a reduction in extraction time and solvent consumption [3,6].

Ultrasound causes cavitation by alternating low-pressure and high-pressure waves in liquids [7]. As the cavitation bubbles collapse, the energy released, leading to an intense shock wave and largely turbulent flow in the liquids. These turbulent flow further produce strong shear forces and damage to plant materials [7]. These mechanical effects of ultrasound have four significant benefits for extraction of plant substance, (a) assisting the release of contents after breaking the cell walls, (b) promoting more penetration of solvent into the interior of the cell and enhancing the mass transfer [8], (c) reducing extraction time at lower processing temperatures [9] and (d) reducing the degradation of products extracted from plants [3]. For ultrasound-mediated plant extraction, the operating parameters such as irradiation time and sonication power were believed to have dependent effects on extraction yield [10,11]. Li et al. [10] reported an ultrasound-assisted extraction of CGA from fresh leaves of Eucommia ulmodies Oliv. They found that the sonication method exhibited highly efficient in the extraction of CGA from E. ulmodies compared with traditional methods. The optimum extraction conditions were found to be aqueous methanol of 70\%, solvent/sample ratio of 20:1 (v/w) and extraction time of $30 \mathrm{~min}$ with three cycles. Moreover, Goltz et al. [12] investigated the extraction process of the phenolic compounds from macela by ultrasonic assistance. They found that ultrasound-assisted extraction not only increased the yield but also improved the antioxidant activity of the extracts. Mazvimba et al. [13] studied the application of heat reflux and ultrasonic-assisted extraction techniques for the extraction of CGA from dry tobacco leaves. Although the heat reflux extraction method with methanol showed high extraction efficiency, the existence of methanol could cause the adulteration of extracts. Ultrasound-assisted aqueous extraction process enhances CGA solubility in water, reduces $25 \%$ of solvent consumption, shortens the extraction time from $3.5 \mathrm{~h}$ per cycle to only 15 min per cycle and improves extraction efficiency from dried tobacco leaves.

Response surface methodology (RSM) has been widely applied to optimize the process of bioactive component extraction, which evaluates the relative importance of each independent variable and determines the optimal operating conditions for the predicted responses. It has been successfully applied to optimize parameters in various chemical processes [14-17]. However, any form of a non-linear relationship between the variables may result in a decrease in the prediction accuracy of the RSM [17]. Recently, an artificial neural network (ANN) has been developed as an alternative to the RSM system for complex non-linear multivariate modeling. ANN performs the project by learning from training examples and does not need any prior knowledge of the correlation between targeted responses $[17,18]$. As compared to the RSM, ANN could be a powerful tool to propose higher accuracy and efficiency on the fitting of experimental responses, prediction, and modeling of biochemical processes [16-18]. Presently, the information about the production of CGA from Lonicera japonica in the ANN system is still limited [13,19].

In this study, the efficiency of CGA extraction was determined by ultrasonic-assisted extraction. On the other hand, RSM and ANN methods were conducted for modeling and optimizing the process of ultrasonic-assisted extraction. The process was performed using a 5-level-4-factor central composite rotatable design (CCRD) to develop RSM and ANN models. Results were statistically compared by the coefficient of correlation determination $\left(R^{2}\right)$, root mean square error (RMSE), and absolute average deviation (AAD). 


\section{Results and Discussion}

\subsection{Single-Factor Experiments}

As shown in Figure 1a, the extraction yield increased as the extraction time increased under the experimental conditions of indicated $\mathrm{L} / \mathrm{S}$ ratio $(10 \mathrm{~mL} / \mathrm{g})$, a reaction temperature of $50{ }^{\circ} \mathrm{C}$, ultrasonic power of $150 \mathrm{~W}$, and ethanol concentration of $75 \%$. When the extraction time was in the range from 0 to $10 \mathrm{~min}$, the yield of CGA tended to rise rapidly and reached a maximum value ( $35 \mathrm{mg} / \mathrm{g})$. When the extraction time continued to increase, the yield of CGA nearly remained constant. Considering the extraction yield and production cost of the process, the extraction time of 10 min was selected for CGA extraction from Lonicera japonica in a further experiment.
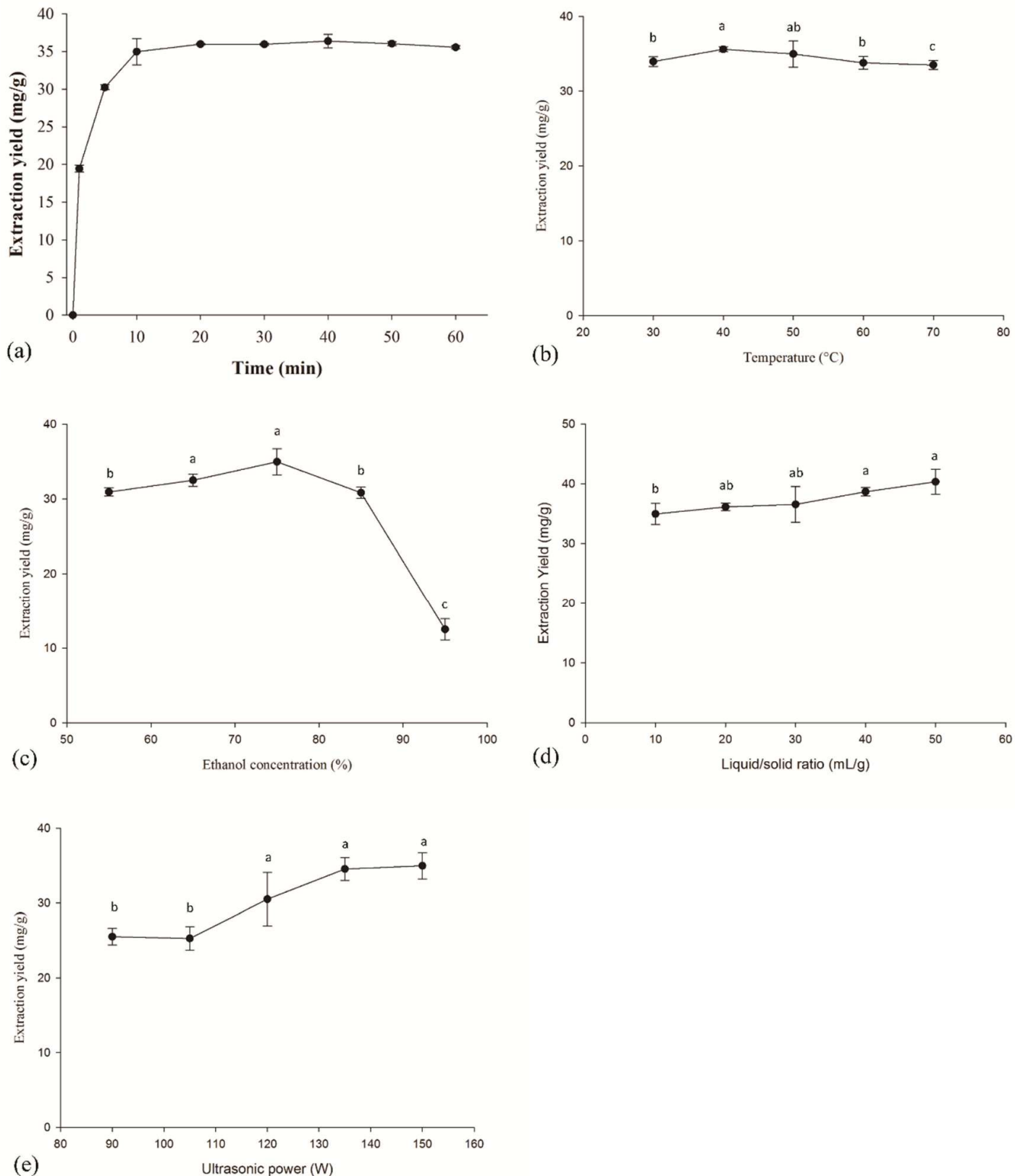

Figure 1. Effect of (a) time, (b) temperature, (c) ethanol concentration, (d) liquid/solid ratio, and (e) ultrasonic power on the yield of CGA. Different letters $a, b$, and c indicate significant differences $(p<0.05)$. 
The effect of extraction temperature on the yield of CGA under the experimental conditions of L/S ratio $(10 \mathrm{~mL} / \mathrm{g})$, an extraction time of $10 \mathrm{~min}$, ultrasonic power of $150 \mathrm{~W}$, and ethanol concentration of $75 \%$, was shown in Figure 1b. The result indicated that the extraction yield of CGA did not significantly vary at different extraction temperatures from $30{ }^{\circ} \mathrm{C}$ to $70{ }^{\circ} \mathrm{C}$. Mazvimba et al. [13] reported that the maximum extraction yield of CGA from tobacco leaves was achieved under $70{ }^{\circ} \mathrm{C}$ of extraction temperature, $3.5 \mathrm{~h}$ of extraction cycle time, and $80 \%$ of methanol. Hu et al. [19] indicated that some chemical structures of phenolic acids might change at a higher temperature, leading to a loss of biological activity. Therefore, performing an extraction at lower temperatures can improve functional properties and reduce energy consumption.

The effects of ethanol concentration on the yield of CGA under the experimental conditions of L/S ratio $(10 \mathrm{~mL} / \mathrm{g})$, an extraction time of $10 \mathrm{~min}$, ultrasonic power of $150 \mathrm{~W}$, and a reaction temperature of $50{ }^{\circ} \mathrm{C}$, was shown in Figure 1c. The extraction yields firstly increased, and then decreased. The maximum yield was observed in $34.96 \mathrm{mg} / \mathrm{g}$ with the treatment of $75 \%$ ethanol concentration. Hu et al. [19] indicated that the use of ethanol at high concentrations might change the solvent polarity, and then the solubility of CGA was affected. Li et al. [10] suggested that 70\% of methanol and 90 min of extraction time could recover the most CGA from leaves of Eucommia ulmodies Oliv.

As shown in Figure 1d, the yield of CGA was increased as the L/S ratio increased. This result can be explained by mass transfer. When a higher solvent to solid ratio was used, the diffusion rate increased, leading to an increase in the extraction yield. However, not only solvent to solid ratio but also temperature and composition of the solution affected the extraction yield of the total phenolic compound [20]. Water/ethanol mixtures as extractants can reduce the generation of free radical from the decomposition of water because ethanol is more stable in terms of homolytic cleavage [3]. Cacace and Mazza [20] studied the optimization efficiency on the extraction of anthocyanins and other phenolic compounds from black currants by using aqueous ethanol. The results showed that the solvent to solid ratio has a critical role in the extraction efficiency of phenolic content. Phenolic content increased as ethanol concentration increased (up to 60\%), and then phenolic content decreased as ethanol concentration further increased. As shown in Figure 1e, the yield of CGA was increased as ultrasonic power increased. The maximum yield was observed at $150 \mathrm{~W}$ of ultrasonic power. Higher power ultrasound exhibited more significant effect on cell damage and therefore improved the extraction efficiency [11].

\subsection{RSM Model}

Temperature, ethanol concentration, L/S ratio, and ultrasonic power are the crucial parameters affecting the extraction efficiency of CGA. In this study, the ranges of optimal temperature, ethanol concentration, L/S ratio, and ultrasonic power were $30-70{ }^{\circ} \mathrm{C}, 55-95 \%, 10-50 \mathrm{~mL} / \mathrm{g}$, and $90-150 \mathrm{~W}$, respectively (Tables 1 and 2). The yields of CGA were obtained between $13.18 \mathrm{mg} / \mathrm{g}$ and $41.64 \mathrm{mg} / \mathrm{g}$. The second-order response model obtained was as follows:

$$
\begin{gathered}
Y(\mathrm{mg} / \mathrm{g})=-344.708589+2.212185 X_{1}+5.044251 X_{2}+3.887346 X_{3}+1.337813 X_{4}+0.008599 X_{1} X_{2} \\
-0.017324 X_{1} X_{3}-0.011583 X_{1} X_{4}-0.012547 X_{2} X_{3}-0.000117 X_{2} X_{4}-0.006649 X_{3} X_{4} \\
-0.007313 X_{1}{ }^{2}-0.03598 X_{2}{ }^{2}-0.015413 X_{3}{ }^{2}-0.002116 X_{4}{ }^{2}
\end{gathered}
$$


Table 1. Coding of experimental parameters and related levels.

\begin{tabular}{cccccccc}
\hline \multirow{2}{*}{ Independent Variable } & \multirow{2}{*}{ Unit } & \multirow{2}{*}{ Symbols } & \multicolumn{5}{c}{ Coded Values } \\
\cline { 4 - 8 } & & & $\mathbf{- 2}$ & $\mathbf{- 1}$ & $\mathbf{0}$ & $\mathbf{+ 1}$ & $\mathbf{+ 2}$ \\
\hline Temperature & ${ }^{\circ} \mathrm{C}$ & $\mathrm{X}_{1}$ & 30 & 40 & 50 & 60 & 70 \\
Ethanol concentration & $\%$ & $\mathrm{X}_{2}$ & 55 & 65 & 75 & 85 & 95 \\
L/S ratio & $\mathrm{mL} / \mathrm{g}$ & $\mathrm{X}_{3}$ & 10 & 20 & 30 & 40 & 50 \\
Ultrasonic power & $\mathrm{W}$ & $\mathrm{X}_{4}$ & 90 & 105 & 120 & 135 & 150 \\
\hline
\end{tabular}

Table 2. Central composite rotatable design (CCRD) and experimental data for 5-level-4-factor response surface analysis.

\begin{tabular}{|c|c|c|c|c|c|c|c|c|c|}
\hline \multirow[t]{2}{*}{ Run } & \multicolumn{4}{|c|}{ Independent Variable ${ }^{a}$} & \multicolumn{5}{|c|}{ Chlorogenic Acid Extraction Yield (mg/g) } \\
\hline & $X_{1}$ & $X_{2}$ & $X_{3}$ & $X_{4}$ & $\begin{array}{c}\text { Experimental } \\
\text { Data }^{b}\end{array}$ & RSM-Predicted & $\begin{array}{c}\text { RSM } \\
\text { Deviation }\end{array}$ & ANN-Predicted & $\begin{array}{c}\text { ANN } \\
\text { Deviation }\end{array}$ \\
\hline 1 & 40 & 65 & 20 & 105 & $20.75 \pm 3.60$ & 25.45 & 4.70 & 20.77 & 0.02 \\
\hline 2 & 60 & 65 & 20 & 105 & $39.41 \pm 1.31$ & 34.99 & 4.42 & 39.37 & 0.04 \\
\hline 3 & 40 & 85 & 20 & 105 & $18.70 \pm 1.92$ & 20.01 & 1.30 & 18.70 & 0.01 \\
\hline 4 & 60 & 85 & 20 & 105 & $35.23 \pm 1.74$ & 32.99 & 2.24 & 35.24 & 0.00 \\
\hline 5 & 40 & 65 & 40 & 105 & $38.02 \pm 3.10$ & 40.56 & 2.55 & 38.01 & 0.00 \\
\hline 6 & 60 & 65 & 40 & 105 & $39.84 \pm 2.06$ & 43.18 & 3.33 & 41.49 & 1.65 \\
\hline 7 & 40 & 85 & 40 & 105 & $34.12 \pm 2.26$ & 30.11 & 4.01 & 34.12 & 0.00 \\
\hline 8 & 60 & 85 & 40 & 105 & $37.67 \pm 2.00$ & 36.16 & 1.51 & 37.66 & 0.01 \\
\hline 9 & 40 & 65 & 20 & 135 & $30.65 \pm 1.29$ & 32.23 & 1.58 & 30.64 & 0.00 \\
\hline 10 & 60 & 65 & 20 & 135 & $30.44 \pm 4.18$ & 34.82 & 4.39 & 30.84 & 0.40 \\
\hline 11 & 40 & 85 & 20 & 135 & $29.68 \pm 3.48$ & 26.72 & 2.96 & 29.66 & 0.01 \\
\hline 12 & 60 & 85 & 20 & 135 & $35.23 \pm 2.62$ & 32.75 & 2.48 & 35.24 & 0.01 \\
\hline 13 & 40 & 65 & 40 & 135 & $40.74 \pm 1.79$ & 43.36 & 2.62 & 43.92 & 3.19 \\
\hline 14 & 60 & 65 & 40 & 135 & $40.25 \pm 2.78$ & 39.02 & 1.23 & 40.62 & 0.37 \\
\hline 15 & 40 & 85 & 40 & 135 & $28.33 \pm 3.10$ & 32.83 & 4.50 & 28.32 & 0.01 \\
\hline 16 & 60 & 85 & 40 & 135 & $36.25 \pm 0.74$ & 31.94 & 4.32 & 35.93 & 0.32 \\
\hline 17 & 30 & 75 & 30 & 120 & $37.59 \pm 1.16$ & 32.67 & 4.92 & 37.94 & 0.36 \\
\hline 18 & 70 & 75 & 30 & 120 & $36.85 \pm 1.17$ & 41.31 & 4.47 & 36.84 & 0.01 \\
\hline 19 & 50 & 55 & 30 & 120 & $38.32 \pm 0.77$ & 31.79 & 6.53 & 38.32 & 0.00 \\
\hline 20 & 50 & 95 & 30 & 120 & $13.18 \pm 2.34$ & 19.26 & 6.08 & 13.18 & 0.00 \\
\hline 21 & 50 & 75 & 10 & 120 & $26.31 \pm 0.95$ & 26.60 & 0.29 & 26.33 & 0.01 \\
\hline 22 & 50 & 75 & 50 & 120 & $41.64 \pm 2.47$ & 40.90 & 0.74 & 41.65 & 0.01 \\
\hline 23 & 50 & 75 & 30 & 90 & $36.35 \pm 1.39$ & 36.73 & 0.38 & 36.36 & 0.00 \\
\hline 24 & 50 & 75 & 30 & 150 & $40.12 \pm 1.57$ & 39.29 & 0.83 & 38.58 & 1.54 \\
\hline 25 & 50 & 75 & 30 & 120 & $39.78 \pm 2.38$ & 39.92 & 0.14 & 39.89 & 0.12 \\
\hline 26 & 50 & 75 & 30 & 120 & $39.99 \pm 2.33$ & 39.92 & 0.07 & 39.89 & 0.10 \\
\hline 27 & 50 & 75 & 30 & 120 & $39.98 \pm 0.35$ & 39.92 & 0.07 & 39.89 & 0.09 \\
\hline
\end{tabular}

As shown in Table 3, the linear term of ethanol concentration $\left(X_{2}\right)$ and L/S ratio $\left(X_{3}\right)$ and the square term of ethanol concentration $\left(X_{2}^{2}\right)$ had significant $(p<0.05)$ influences on the yield of CGA. The variance analysis of the model showed that the $p$ value for the model was 0.0238 , indicating that the model was significant and could monitor the optimization [21]. However, the $R^{2}$ value was 0.7913 , indicating that the model only explained $79.13 \%$ of the variation in the data. Moreover, the lack-of-fit $(p<0.05)$ was significant, suggesting that the regression model was inadequate to describe the observed data variations. Therefore, ANN was used to improve and obtain a more precise prediction. 
Table 3. ANOVA for the experimental results of central-composite rotatable design (CCRD).

\begin{tabular}{|c|c|c|c|c|c|}
\hline Source & Sum of Squares & DF & Mean Square & F Value & $\begin{array}{l}p \text {-Value } \\
\text { Prob }>\text { F }\end{array}$ \\
\hline Model & 1113.03 & 14 & 79.5 & 3.25 & 0.0238 * \\
\hline $\mathrm{X}_{1}$ & 112.13 & 1 & 112.13 & 4.58 & 0.0535 \\
\hline$x_{2}$ & 235.33 & 1 & 235.33 & 9.62 & $0.0092 *$ \\
\hline$x_{3}$ & 306.68 & 1 & 306.68 & 12.54 & $0.0041 *$ \\
\hline$x_{4}$ & 9.82 & 1 & 9.82 & 0.4 & 0.5382 \\
\hline$X_{1} X_{2}$ & 11.83 & 1 & 11.83 & 0.48 & 0.5 \\
\hline$x_{1} x_{3}$ & 48.02 & 1 & 48.02 & 1.96 & 0.1865 \\
\hline$x_{1} x_{4}$ & 48.3 & 1 & 48.3 & 1.97 & 0.1853 \\
\hline$X_{2} X_{3}$ & 25.19 & 1 & 25.19 & 1.03 & 0.3302 \\
\hline$X_{2} X_{4}$ & $4.889 \times 10^{-3}$ & 1 & $4.889 \times 10^{-3}$ & $1.998 \times 10^{-4}$ & 0.989 \\
\hline$X_{3} X_{4}$ & 15.91 & 1 & 15.91 & 0.65 & 0.4356 \\
\hline $\mathrm{X}_{1}^{2}$ & 11.41 & 1 & 11.41 & 0.47 & 0.5076 \\
\hline$x_{2}^{2}$ & 276.17 & 1 & 276.17 & 11.29 & 0.0057 * \\
\hline$x_{3}^{2}$ & 50.68 & 1 & 50.68 & 2.07 & 0.1756 \\
\hline$X_{4}^{2}$ & 4.84 & 1 & 4.84 & 0.2 & 0.6645 \\
\hline Residual & 293.55 & 12 & 24.46 & & \\
\hline Lack of Fit & 293.52 & 10 & 29.35 & 1983.46 & $0.0005^{*}$ \\
\hline Pure Error & 0.03 & 2 & 0.015 & & \\
\hline Cor Total & 1406.58 & 26 & & & \\
\hline Std. Dev. & & 4.95 & R-Squared & \multicolumn{2}{|c|}{0.7913} \\
\hline Mean & & 34.27 & Adj R-Squared & \multirow{3}{*}{\multicolumn{2}{|c|}{0.5478}} \\
\hline $\mathrm{CV} \%$ & & 14.43 & & & \\
\hline PRESS & & 1690.75 & & & \\
\hline
\end{tabular}

Independent variable $\mathrm{X}_{1}$ : Temperature $\left({ }^{\circ} \mathrm{C}\right), \mathrm{X}_{2}$ : Ethanol concentration $(\%), \mathrm{X}_{3}$ : Liquid/solid ratio $(\mathrm{mL} / \mathrm{g}), \mathrm{X}_{4}$ : Ultrasonic power $(\mathrm{W}) .{ }^{*}$ Significant at $p$-value less than 0.05 .

\subsection{ANN Model}

ANN was an effective tool for modeling unknown or semi-unknown processes. It has been applied in modeling to control the nonlinear multivariate process [22]. ANN can improve prediction accuracy to optimize the process condition of extraction from Lonicera japonica. In this study, $70 \%$ of the CCRD data (Table 2) were used to train the neural network model, $15 \%$ of the CCRD data were used to test, and $15 \%$ of the CCRD data were used to verify. The experimental data was divided into three parts in order to measure the performance of the neural network and predict the unobserved data [23]. Various learning algorithms were tested for training neural network models, and the best ANN model with a 4-10-1 topology was finally established (Figure 2). Figure 3 indicated that the neural network between the experimental and predicted data for training, testing, and validation fitted well. To conclude, the new construction ANN model can predict the yield of CGA.

Table 2 indicates that the extraction yield predicted by ANN were superior to those predicted by RSM. The ANN-predicted values were very close to the actual yields. However, there was some difference between the predicted values of RSM and the actual yields (Table 2). As shown in Figure 4, the effect of each pair of independent variables on the yields of CGA was shown using contour plots. Figure $4 \mathrm{a}$ indicates that the maximum yield was found when the ethanol concentration was $65-75 \%$ and that the $\mathrm{L} / \mathrm{S}$ ratio was $30-50 \mathrm{~mL} / \mathrm{g}$. The changes in extraction yield are related to the polarity of the solvent [19]. Figure $4 \mathrm{~b}$ illustrates the effects of ethanol concentration and ultrasound power on the extraction yield, indicating that the highest yield was obtained by treatment with ethanol concentration between $65 \%$ and $75 \%$, but ultrasound power had no effect on extraction yield. Figure $4 \mathrm{c}$ illustrates the effects of $\mathrm{L} / \mathrm{S}$ ratio and temperature on extraction yield, indicating that the maximum yield was obtained at L/S ratio of $30-50 \mathrm{~mL} / \mathrm{g}$, while the temperature increasing from $40-60{ }^{\circ} \mathrm{C}$ did not increase the yield. As the liquid to solid ratio increased, the effect of temperature on yield decreased. Figure $4 \mathrm{~d}$ illustrates that the maximum yield was observed at an ethanol concentration range of $65-75 \%$ and a 
temperature range of $50-70^{\circ} \mathrm{C}$, while there was no increase in yield over this temperature range. The contour plot showed that an extraction temperature above $70^{\circ} \mathrm{C}$ might have similar extraction yield to a temperature range of $50-70{ }^{\circ} \mathrm{C}$, however, the higher extraction temperature may cause CGA to be affected by temperature. Wianowska and Gil [3] indicated that CGA was prone to intramolecular isomerization, transesterification, and degradation at high temperatures. On the other hand, the results of the single factor experiment (Figure $1 \mathrm{~b}$ ) showed that the yield of CGA gradually decreased above $40{ }^{\circ} \mathrm{C}$. Therefore, the experimental design did not perform a higher extraction temperature to investigate the extraction yield. Figure $4 \mathrm{e}-\mathrm{f}$ illustrates that the highest yield was observed at an $\mathrm{L} / \mathrm{S}$ ratio between $30 \mathrm{~mL} / \mathrm{g}$ and $50 \mathrm{~mL} / \mathrm{g}$, while the temperature increasing from 50 to $70{ }^{\circ} \mathrm{C}$ did not increase the yield. It can be found that except for the ultrasonic power, the extraction temperature, the liquid-solid ratio, and the ethanol concentration are important parameters affecting the yield. At a fixed temperature $\left(50^{\circ} \mathrm{C}\right)$, it can observe that the ultrasonic effect on CGA extraction is significant (Figure 1e). At lower temperature $\left(30-50^{\circ} \mathrm{C}\right)$, the extraction yields increased with increasing ultrasonic power. The increase of ultrasonic power led to more rapid speed to generate cavitation. Thus, the extraction process was enhanced [24]. However, the increased temperature may accelerate the formation of free radicals during the ultrasonic process [25]. Thus, the total phenolic content decreased [25]. This phenomenon may explain why ultrasonic power has a less significant effect on yield in RSM modeling (Figure 4f). A contour plot of the experimental model described the relationship between the two factors and the response; an elliptical contour plot indicated the interactions between the factors were significant. The red area of the contour plot showed the range of high extraction yields, and extraction temperatures were interpreted in the ranges of $30-70{ }^{\circ} \mathrm{C}$ (Figure $4 \mathrm{c}, \mathrm{d}, \mathrm{f}$ ). However, the maximum response operating condition based on the interaction between the four factors. Therefore, the most appropriate extraction temperature was not in the range of $50-70{ }^{\circ} \mathrm{C}$.

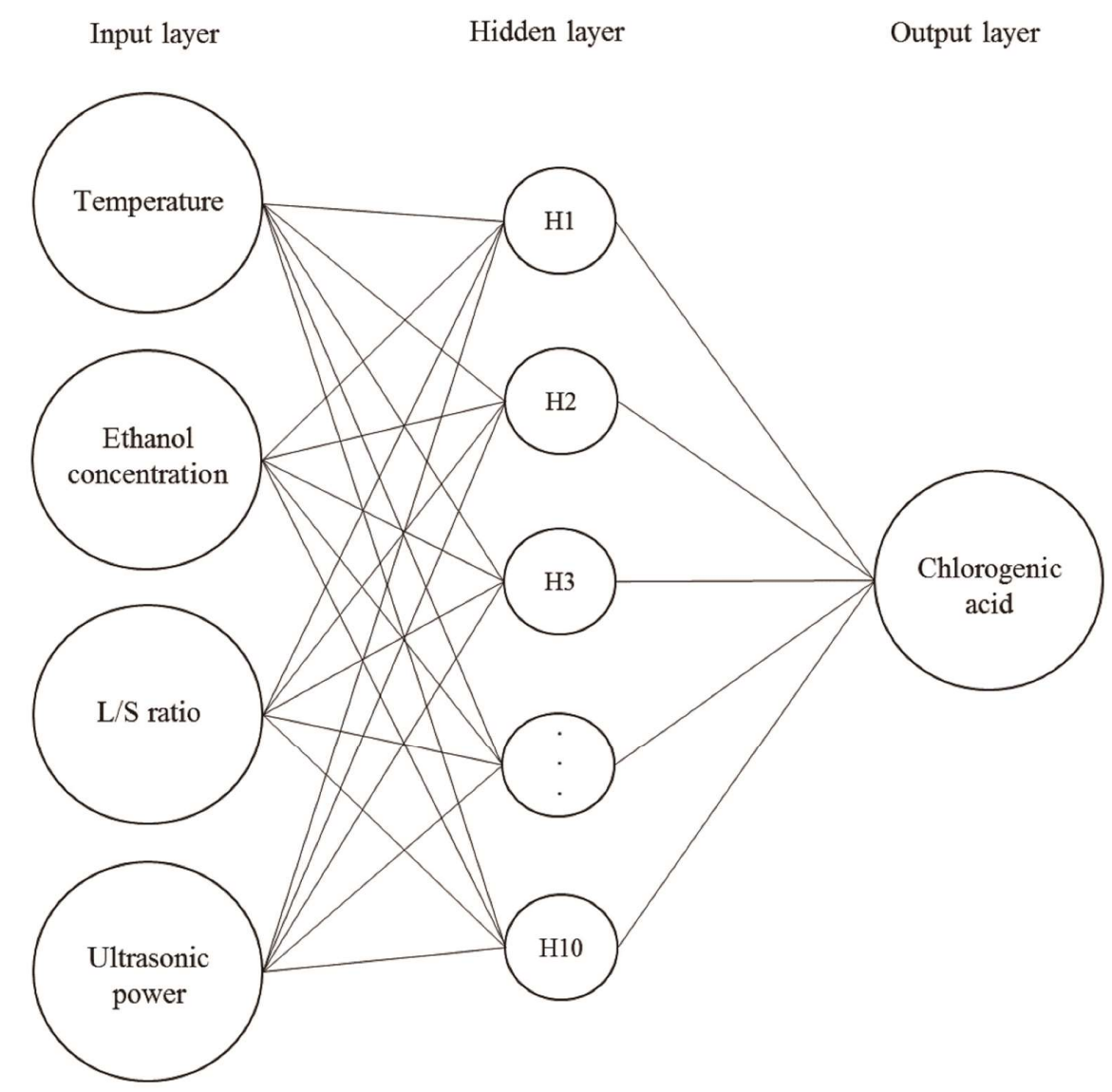

Figure 2. Neural network topology. The topology of multilayer feed forward neural network for the estimation of ultrasound-assisted extraction of chlorogenic acid (CGA). 

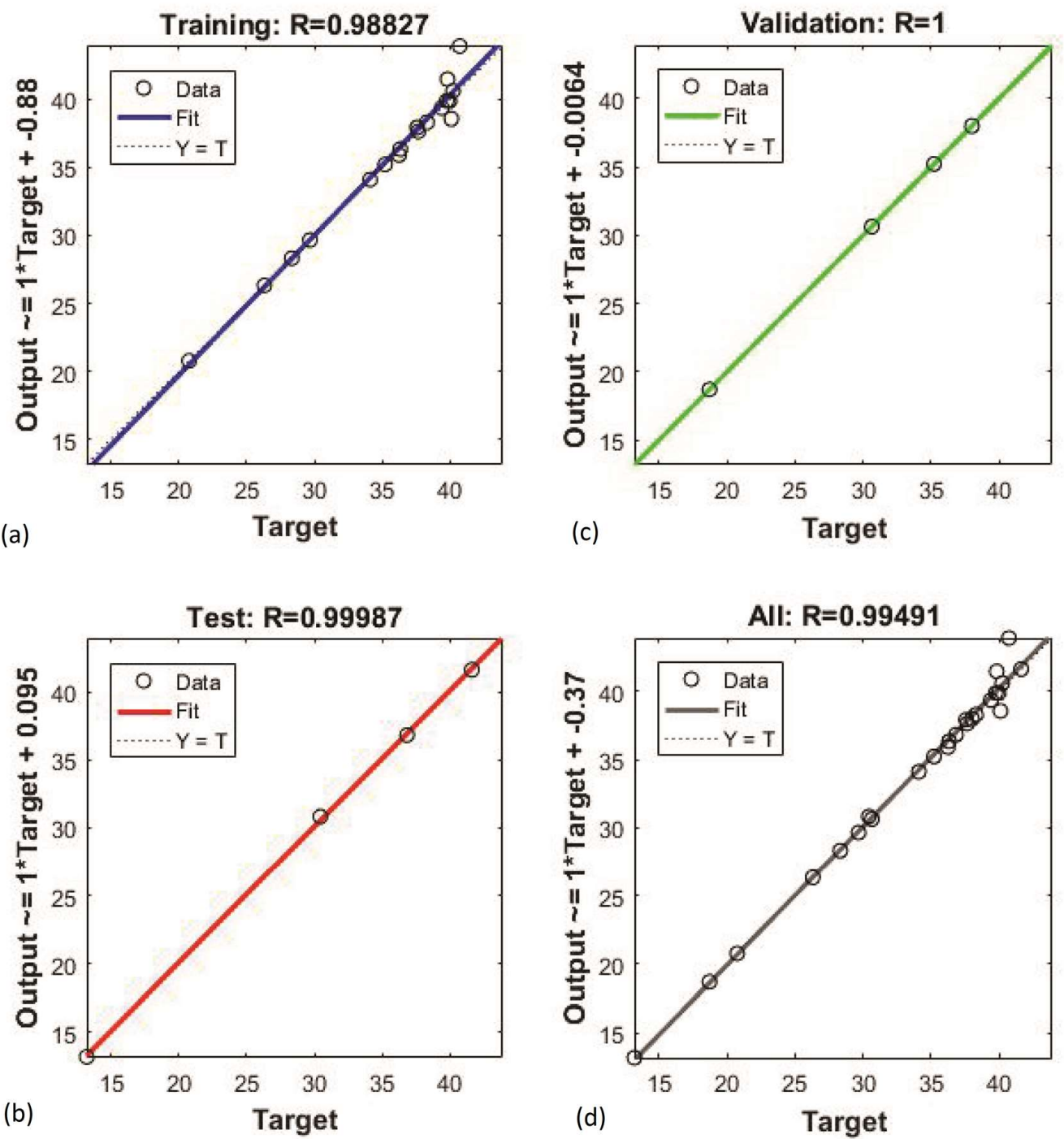

Figure 3. Scatter plot between experimental and predicted yield by artificial neural network (ANN) for (a) training, (b) testing, (c) validation, and (d) overall data fitting. 


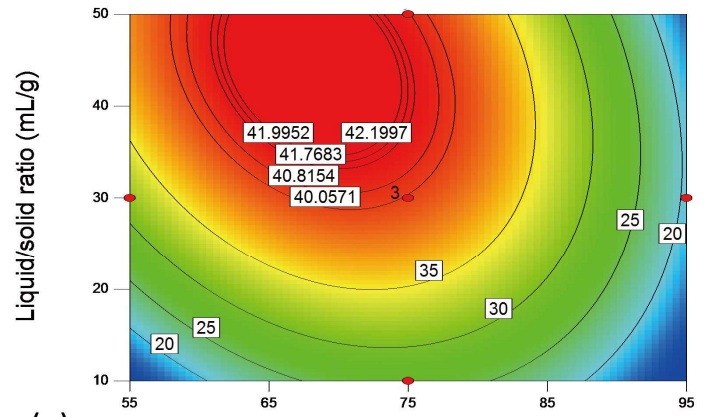

(a)

Ethanol concentration (\%)

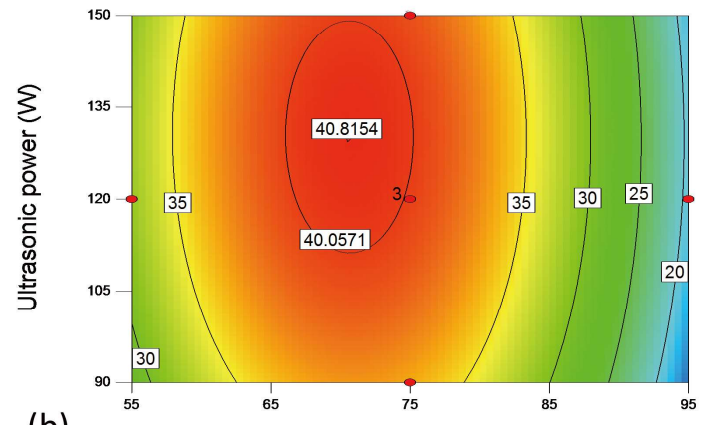

(b)

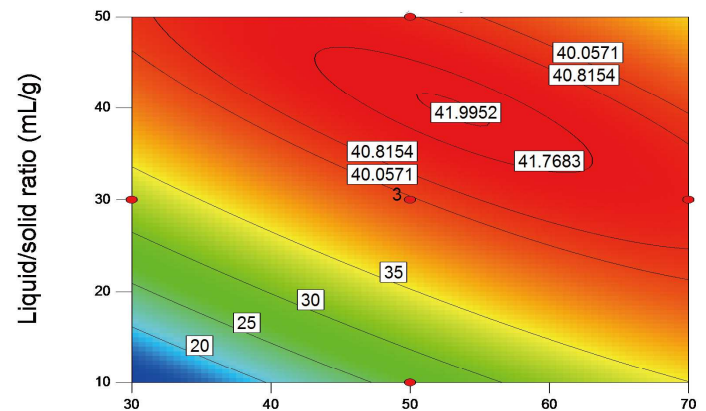

(c)

Temperature $\left({ }^{\circ} \mathrm{C}\right)$

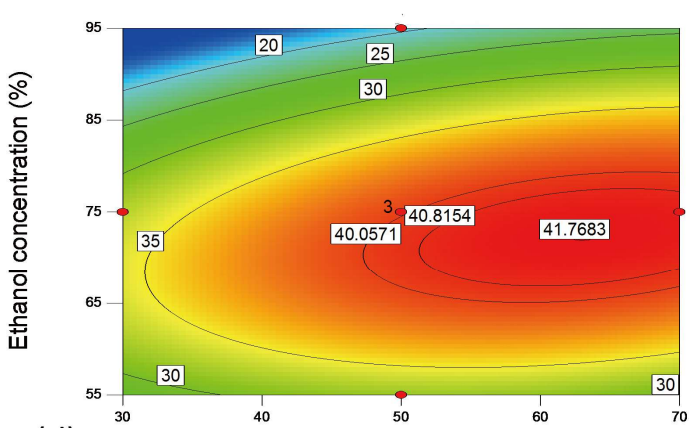

(d)

Temperature $\left({ }^{\circ} \mathrm{C}\right)$

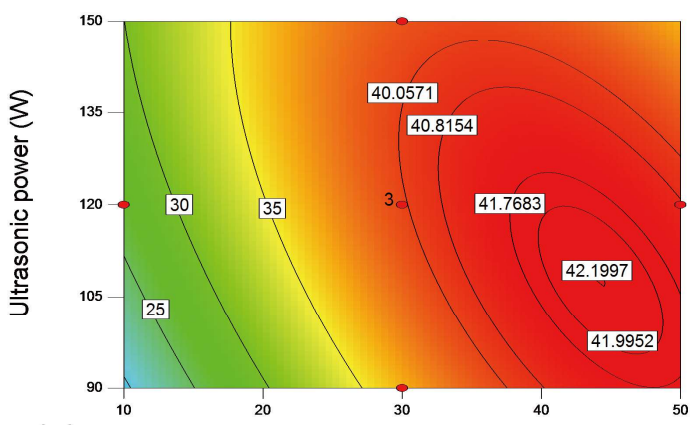

(e)

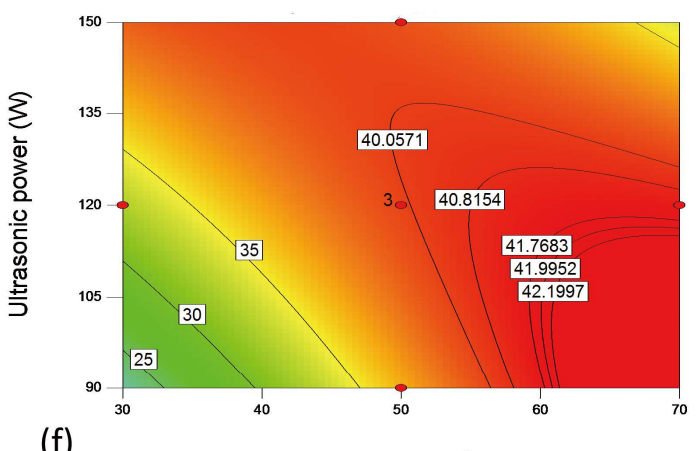

Temperature $\left({ }^{\circ} \mathrm{C}\right)$

Figure 4. Contour plots are showing the relationships between responses variable and independent variables. (a) Ethanol concentration compared to L/S ratio; (b) ultrasonic power compared to ethanol concentration; (c) L/S ratio compared to temperature; (d) ethanol concentration compared to temperature; (e) ultrasonic power compared to L/S ratio; (f) ultrasonic power compared to temperature.

\subsection{Verification, Comparison and Optimization}

In order to verify the predictive capability of both the ANN and RSM models, a new set of experimental condition combinations was performed and did not part of the training data set (Table 4). Table 5 shows the statistical comparison of the RSM and ANN models. $R^{2}$ values for constructed RSM and ANN were exhibited as 0.7913 and 0.9898 (Figure 5). It indicated that the ANN model has better performance for prediction than RSM. The RMSE for RSM and ANN was found as 1.9050 and 0.7006 . The AAD for RSM and ANN was found as 1.6541 and 0.4204. Compared with the ANN model, RSM had a higher prediction error. From the results, the prediction of the ANN model has higher prediction accuracy in approximating the actual experimental values. 
Table 4. Validation experiments for the ultrasound-assisted extraction of CGA.

\begin{tabular}{|c|c|c|c|c|c|c|c|c|c|}
\hline \multirow{2}{*}{ Run } & \multicolumn{4}{|c|}{ Independent Variable ${ }^{a}$} & \multicolumn{5}{|c|}{ Chlorogenic Acid Extraction Yield (mg/g) } \\
\hline & $x_{1}$ & $X_{2}$ & $X_{3}$ & $\mathrm{X}_{4}$ & $\begin{array}{l}\text { Experimental } \\
\text { Data } b\end{array}$ & RSM-Predicted & $\begin{array}{c}\text { RSM } \\
\text { Deviation }\end{array}$ & ANN-Predicted & $\begin{array}{c}\text { ANN } \\
\text { Deviation }\end{array}$ \\
\hline 1 & 60 & 65 & 30 & 120 & $39.65 \pm 0.97$ & 40.02 & 0.37 & 39.98 & 0.33 \\
\hline 2 & 50 & 75 & 20 & 135 & $34.45 \pm 2.17$ & 35.96 & 1.51 & 33.29 & 1.16 \\
\hline 3 & 60 & 75 & 30 & 135 & $37.70 \pm 3.13$ & 39.77 & 2.07 & 36.69 & 1.01 \\
\hline 4 & 50 & 65 & 20 & 120 & $33.70 \pm 2.55$ & 33.08 & 0.62 & 33.82 & 0.12 \\
\hline
\end{tabular}

Table 5. Comparison of optimization and prediction capabilities of ANN and response surface methodology (RSM) for CGA extraction.

\begin{tabular}{ccc}
\hline Parameters $^{\text {a }}$ & RSM & ANN \\
\hline$R^{2}$ & 0.7913 & 0.9898 \\
RMSE & 1.9050 & 0.7006 \\
AAD & 1.6541 & 0.4204
\end{tabular}

a AAD: Absolute average deviation (\%); RMSE: Root mean square error; $R^{2}$ : Coefficient of correlation determination.
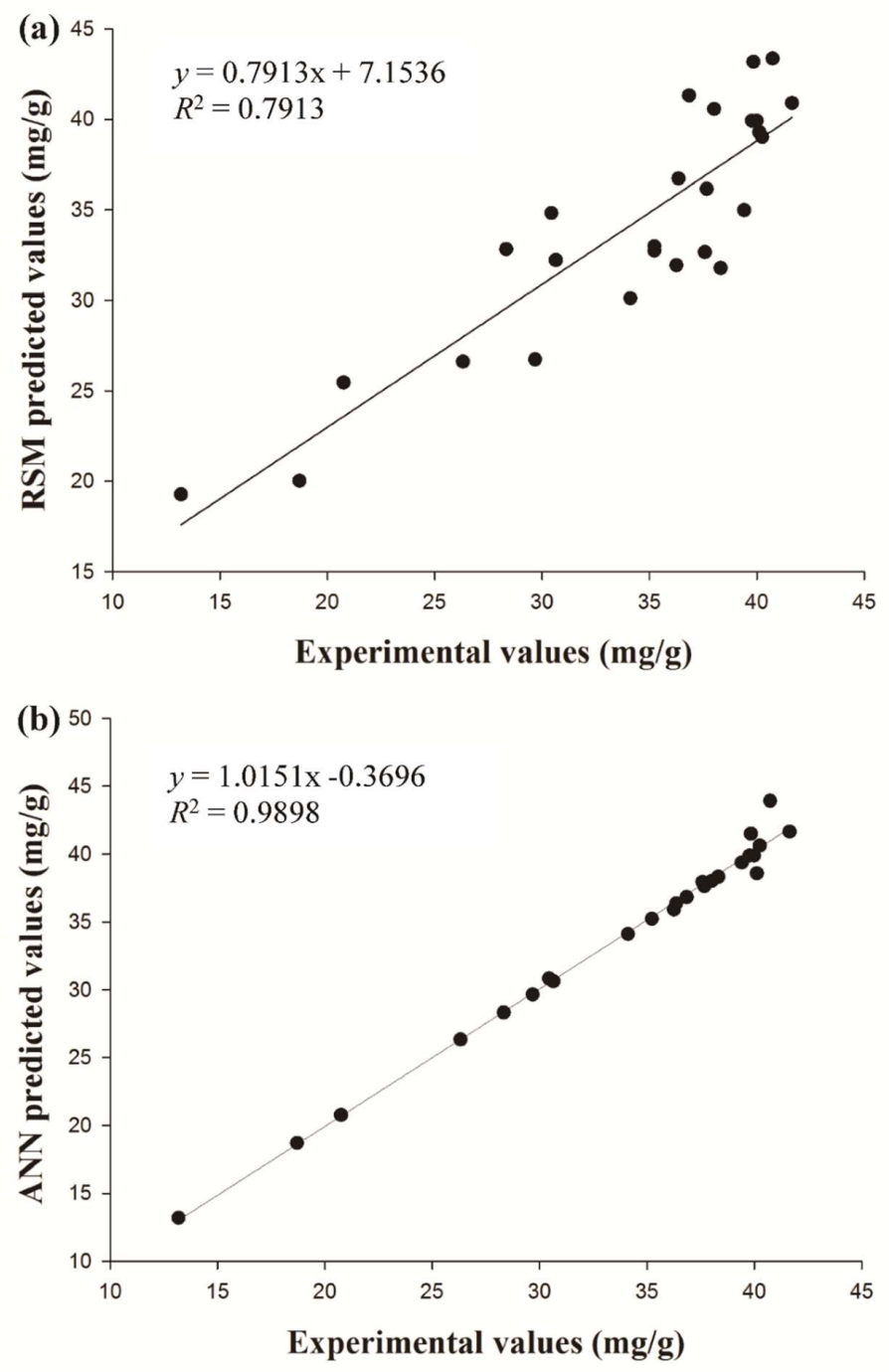

Figure 5. Comparison of experimental data with the predicted value obtained by (a) the RSM and (b) ANN models. 
The following optimal conditions for ultrasound-assisted extraction for CGA from Lonicera japonica were determined using a ridge max analysis of an experimental model: Temperature $\left(X_{1}\right), 33.56{ }^{\circ} \mathrm{C}$; ethanol concentration $\left(X_{2}\right), 65.88 \%$; $\mathrm{L} / \mathrm{S}$ ratio $\left(X_{3}\right), 46 \mathrm{~mL} / \mathrm{g}$; and ultrasonic power $\left(X_{4}\right), 150 \mathrm{~W}$; the maximum yield was predicted to be $45.63 \mathrm{mg} / \mathrm{g}$ and $44.78 \mathrm{mg} / \mathrm{g}$ from the RSM and ANN model, respectively. Under these conditions, the actual experimental yield was $43.13 \mathrm{mg} / \mathrm{g}$. The results confirmed that the constructed model adequately predicted the extraction yield of CGA. However, it has been proven again that the prediction ability of ANN was superior to RSM, and an optimum condition of extraction can be obtained more accurately. Compared to literature, $\mathrm{Xu}$ et al. [24] indicated that $37.07 \mathrm{mg} / \mathrm{g}$ of CGA was obtained by ultrasound-assisted extraction using a response surface methodology. Lin et al. [15] developed the enzyme-assisted ultrasonic extraction of resveratrol from P. cuspidatum, suggesting that the ANN model demonstrated more accurately in data fitting as compared to the RSM model. The results are consistent with this study. The present study demonstrated that under multi-variable-multi-level operating conditions, ANN modeling could replace RSM modeling as an operational tool for optimizing processes.

\section{Materials and Methods}

\subsection{Materials}

Lonicera japonica powder was purchased from He-Kang Chinese Medicine Co. (New Taipei City, Taiwan). CGA was purchased from Acros Organics (Pittsburgh, PA, USA). Ethanol was purchased from Taiwan Tobacco \& Liquor Corporation (Taipei, Taiwan). Methanol was purchased from Aencore Chemical Co. (New South Wales, Australia). Acetic acid was purchased from Sigma-Aldrich Co. (St. Louis, MO, USA). All other chemicals and reagents were analytic grade.

\subsection{Conventional Shaking Extraction of CGA from Lonicera japonica}

The extracts were prepared according to the method of Chen et al. [14] and Hsu et al. [26]. Lonicera japonica flowers powder $(0.1 \mathrm{~g})$ was mixed with $1 \mathrm{~mL}$ of $75 \% \mathrm{EtOH}$ in a cap-sealed glass tube. The mixture was extracted at $50{ }^{\circ} \mathrm{C}$ for various times in an orbital shaking bath (100 rpm). After extraction, the supernatant of the sample was collected by centrifugation (C2400-P, Labnet International, Inc., Cary, NC, USA) at 13,000 rpm for $10 \mathrm{~min}$. The supernatants were filtered through a $0.45 \mu \mathrm{m}$ PVDF syringe filter and stored in a dark room at $4{ }^{\circ} \mathrm{C}$ until analysis.

\subsection{Ultrasonic-Assisted Extraction of CGA from Lonicera japonica}

Lonicera japonica flowers powder $(0.1 \mathrm{~g})$ was mixed with $1 \mathrm{~mL}$ of $75 \% \mathrm{EtOH}$ in a cap-sealed glass tube. The mixture was extracted at $50{ }^{\circ} \mathrm{C}$ and $150 \mathrm{~W}$ of ultrasonic power with various times in an ultrasonic bath $(40 \mathrm{kHz}$, Delta DC150H, Dogger Science, New Taipei, Taiwan). After extraction, the supernatant of the sample was collected by centrifugation at 13,000 rpm for $10 \mathrm{~min}$. The supernatants were filtered through a $0.45 \mu \mathrm{m}$ PVDF syringe filter and stored in a dark room at $4{ }^{\circ} \mathrm{C}$ until analysis.

\subsection{HPLC Analysis of Products Extracted from Lonicera japonica}

The extracts of Lonicera japonica were analyzed by high-performance liquid chromatography (HPLC) (Hitachi L-7400; Tokyo, Japan) according to the method described by Lin et al. [15]. Twenty $\mu \mathrm{L}$ of the extract was loaded into a Thermo C18 capillary column $(5 \mu \mathrm{m}, 250 \times 4.6 \mathrm{~mm}$, Agilent, Waltham, MA, USA) and assayed in gradient elution mode during the chromatographic analysis. Elution was carried out using $0.1 \%$ acetic acid in water and methanol at a flow rate of $1.0 \mathrm{~mL} / \mathrm{min}$. Gradient elution was performed as follows: Methanol was set $30 \%$ for the first $5 \mathrm{~min}$, then the methanol was increased to $50 \%$ between 5 and $10 \mathrm{~min}$, and held at $100 \%$ for the last $5 \mathrm{~min}$. The UV detector was set at a wavelength of $325 \mathrm{~nm}$. Calibration curves were established using CGA standards, and samples were 
analyzed by comparing their retention times with those of the standards. The yield of CGA from Lonicera japonica was calculated according to the following formula Equation (2):

Extraction yield $(\mathrm{mg} / \mathrm{g})=$ mass of the compound in extraction solution $(\mathrm{mg}) / \mathrm{mass}$ of dried material (g)

\subsection{Response Surface Methodology (RSM)}

In this study, a 5-level-4-factor central composite rotatable design (CCRD), including 27 treatments, was employed. To avoid any unknown factor that may affect the experiment, the 27 runs were performed in random order. The independent variables of extraction temperature $\left(30-70{ }^{\circ} \mathrm{C}\right)$, ethanol concentration (55-95\%), L/S ratio (10:1-50:1 mL/g), and ultrasonic power $(90-150 \mathrm{~W})$ are presented in Table 1. Table 2 shows the independent factors, levels, and design matrix for the experiment. All reactions were carried out in duplicate. Regression analysis was performed for the experiment data by using Design-Expert (Version 8.0.6.1, Stat-Ease Inc., Minneapolis, MN, USA) software to fit the following second-order response model:

$$
\begin{gathered}
Y=\beta_{0}+\beta_{1} X_{1}+\beta_{2} X_{2}+\beta_{3} X_{3}+\beta_{4} X_{4}+\beta_{12} X_{1} X_{2}+\beta_{13} X_{1} X_{3}+\beta_{14} X_{1} X_{4}+\beta_{23} X_{2} X_{3}+\beta_{24} X_{2} X_{4}+\beta_{34} X_{3} X_{4} \\
+\beta_{11} X_{1}^{2}+\beta_{22} X_{2}{ }^{2}+\beta_{33} X_{3}{ }^{2}+\beta_{44} X_{4}{ }^{2}
\end{gathered}
$$

where $Y$ represents the response variable and $\beta_{0}$ is the constant term; $\beta_{1}, \beta_{2}, \beta_{3}$ and $\beta_{4}$ are coefficients of the linear effects, $\beta_{11}, \beta_{22}, \beta_{33}$ and $\beta_{44}$ are coefficients of quadratic effects and $\beta_{12}, \beta_{13}, \beta_{14}, \beta_{23}, \beta_{24}$ and $\beta_{34}$ are coefficients of interaction effects for the four independent variables $\left(X_{1}=\right.$ temperature, $X_{2}=$ ethanol concentration, $X_{3}=\mathrm{L} / \mathrm{S}$ ratio, $X_{4}=$ ultrasonic power).

\subsection{Artificial Neural Network (ANN)}

A multi-layer perceptron (MLP) based feed-forward ANN was applied for modeling ultrasonic-assisted extraction of CGA. A commercial ANN software, MATLAB version R2016a (MathWorks software, MathWorks Inc., Natick, MA, USA) was used in the study. The experimental data was constructed by the regression-based network approach. The network architecture consisted of an input layer with four neurons (temperature, ethanol concentration, L/S ratio, and ultrasonic power), an output layer with one neuron, which represented the extraction yield of CGA, and one hidden layer with ten neurons. A schematic diagram of the MLP architecture can be observed in Figure 2. BFGS quasi-Newton backpropagation (TRAINBFG) was an efficient training function because it has good performance in non-smooth optimizations and smaller networks [27]. Gradient descent method (LEARNGDM) as the adaptive learning function was used to minimize the mean squared error (MSE) between the network output and the actual error rate [28]. Mean squared normalized error performance function can appraise the network's performance according to the MSE. The hyperbolic tangent sigmoid transfer function (TANSIG) and linear transfer function (PURELIN) were used to calculate a layer's output from its net input [29]. All these functions were used to train the neural network and built the best ANN.

\subsection{Comparison of Prediction Capability between ANN and RSM for CGA Extraction}

Several statistical parameters, including the coefficient of determination $\left(R^{2}\right)$, root mean square error (RMSE) and absolute average deviation (AAD), were calculated for the comparison of estimation capabilities of RSM and ANN[15] as shown in Equations (4) to (6), respectively.

$$
R^{2}=1-\frac{\sum_{\mathrm{i}=1}^{\mathrm{n}}\left(\mathrm{Y}_{\text {pre }}-\mathrm{Y}_{\exp }\right)^{2}}{\sum_{\mathrm{i}=1}^{\mathrm{n}}\left(\mathrm{Y}_{\mathrm{m}}-\mathrm{Y}_{\exp }\right)^{2}}
$$




$$
\begin{gathered}
\text { RMSE }=\sqrt{\frac{\sum_{i=1}^{n}\left(Y_{\text {pre }}-Y_{\text {exp }}\right)^{2}}{n}} \\
\text { AAD }=\left[\frac{\sum_{i=1}^{n}\left(\mid Y_{\text {exp }}-Y_{\text {pre }} / Y_{\text {pre }}\right)}{n}\right] \times 100
\end{gathered}
$$

where $Y_{\text {pre }}$ is the predicted CGA extraction yield (by either RSM or ANN), $Y_{\exp }$ is the observed CGA extraction yield, $Y_{m}$ is the average CGA extraction yield, and $n$ is the number of experiments $(n=27$ for CCRD experiments and $n=4$ for external experiments).

\section{Conclusions}

The yield of CGA reached $43.13 \mathrm{mg} / \mathrm{g}$ under the optimal conditions, which were as follows: Temperature, $33.56{ }^{\circ} \mathrm{C}$; ethanol concentration, $65.88 \%$; L/S ratio, $46: 1 \mathrm{~mL} / \mathrm{g}$; and ultrasound power, 150 W. Despite recent decade's advances in the ultrasound-assisted extraction of CGA by applying response surface methodology, some complex nonlinear factors still lead to the significant lack of fit in the optimization process, especially the interaction between multiple factors. In this study, ANN modeling has successfully employed the ultrasound-assisted extraction of CGA. The constructed ANN shows high $R^{2}$ values as 0.9898 , whereas AAD and RMSE values had a smaller value as compared to those observed from the RSM. In conclusion, the application of ANN in ultrasound-assisted extraction of Lonicera japonica can obtain more CGA nutraceuticals, which has potential commercial applications.

Author Contributions: H.-C.Y. verified and wrote the manuscript. W.-M.L. implemented the experiments. S.-M.H. and C.-H.K. revised the manuscript. C.-J.S. conceptualized and supervised this research. All authors agreed with the final version of the manuscript.

Funding: This research received no external funding.

Acknowledgments: The authors are very grateful to the Ministry of Science and Technology, Taiwan, R.O.C., for supporting this research (Grants No. 107-2320-B-005-012-MY3).

Conflicts of Interest: The authors declare no conflict of interest.

\section{References}

1. Liang, N.; Kitts, D.D. Role of Chlorogenic Acids in Controlling Oxidative and Inflammatory Stress Conditions. Nutrients 2016, 8, 16. [CrossRef] [PubMed]

2. Naveed, M.; Hejazi, V.; Abbas, M.; Kamboh, A.A.; Khan, G.J.; Shumzaid, M.; Ahmad, F.; Babazadeh, D.; Xia, F.; Modarresi-Ghazani, F.; et al. Chlorogenic acid (CGA): A pharmacological review and call for further research. Biomed. Pharmacother. 2018, 97, 67-74. [CrossRef] [PubMed]

3. Wianowska, D.; Gil, M. Recent advances in extraction and analysis procedures of natural chlorogenic acids. Phytochem. Rev. 2019, 18, 273-302. [CrossRef]

4. Budryn, G.; Nebesny, E.; Oracz, J. Correlation between the stability of chlorogenic acids, antioxidant activity and acrylamide content in coffee beans roasted in different conditions. Int. J. Food Prop. 2015, 18, 290-302. [CrossRef]

5. Wang, L.; Weller, C.L. Recent advances in extraction of nutraceuticals from plants. Trends Food Sci. Technol. 2006, 17, 300-312. [CrossRef]

6. Vinatoru, M. An overview of the ultrasonically assisted extraction of bioactive principles from herbs. Ultrason. Sonochem. 2001, 8, 303-313. [CrossRef]

7. Azmir, J.; Zaidul, I.; Rahman, M.; Sharif, K.; Mohamed, A.; Sahena, F.; Jahurul, M.; Ghafoor, K.; Norulaini, N.; Omar, A. Techniques for extraction of bioactive compounds from plant materials: A review. J. Food Eng. 2013, 117, 426-436. [CrossRef]

8. Srinath, D.; Maheswari, K. Ultrasound technology in food processing: A review. Int. J. Curr. Adv. Res. 2016, $5,778-783$. 
9. Dent, M.; Dragovic-Uzelac, V.; Garofulic, I.E.; Bosiljkov, T.; Jezek, D.; Brncic, M. Comparison of Conventional and Ultrasound-assisted Extraction Techniques on Mass Fraction of Phenolic Compounds from Sage (Salvia officinalis L.). Chem. Biochem. Eng. Q. 2015, 29, 475-484. [CrossRef]

10. Li, H.; Chen, B.; Yao, S. Application of ultrasonic technique for extracting chlorogenic acid from Eucommia ulmodies Oliv. (E. ulmodies). Ultrason. Sonochem. 2005, 12, 295-300. [CrossRef] [PubMed]

11. Da Porto, C.; Porretto, E.; Decorti, D. Comparison of ultrasound-assisted extraction with conventional extraction methods of oil and polyphenols from grape (Vitis vinifera L.) seeds. Ultrason. Sonochem. 2013, 20, 1076-1080. [CrossRef] [PubMed]

12. Goltz, C.; Ávila, S.; Barbieri, J.B.; Igarashi-Mafra, L.; Mafra, M.R. Ultrasound-assisted extraction of phenolic compounds from Macela (Achyrolcine satureioides) extracts. Ind. Crops Prod. 2018, 115, 227-234. [CrossRef]

13. Mazvimba, M.T.; Yu, Y.; Cui, Z.-Q.; Zhang, Y. Optimization and orthogonal design of an ultrasonic-assisted aqueous extraction process for extracting chlorogenic acid from dry tobacco leaves. Chin. J. Nat. Med. 2012, 10, 311-320. [CrossRef]

14. Chen, B.-Y.; Kuo, C.-H.; Liu, Y.-C.; Ye, L.-Y.; Chen, J.-H.; Shieh, C.-J. Ultrasonic-assisted extraction of the botanical dietary supplement resveratrol and other constituents of Polygonum cuspidatum. J. Nat. Prod. 2012, 75, 1810-1813. [CrossRef] [PubMed]

15. Lin, J.-A.; Kuo, C.-H.; Chen, B.-Y.; Li, Y.; Liu, Y.-C.; Chen, J.-H.; Shieh, C.-J. A novel enzyme-assisted ultrasonic approach for highly efficient extraction of resveratrol from Polygonum cuspidatum. Ultrason. Sonochem. 2016, 32, 258-264. [CrossRef] [PubMed]

16. Kuo, C.-H.; Liu, T.-A.; Chen, J.-H.; Chang, C.-M. J.; Shieh, C.-J. Response surface methodology and artificial neural network optimized synthesis of enzymatic 2-phenylethyl acetate in a solvent-free system. Biocatal. Agric. Biotechnol. 2014, 3, 1-6. [CrossRef]

17. Desai, K.M.; Survase, S.A.; Saudagar, P.S.; Lele, S.; Singhal, R.S. Comparison of artificial neural network $(\mathrm{ANN})$ and response surface methodology (RSM) in fermentation media optimization: Case study of fermentative production of scleroglucan. Biochem. Eng. J. 2008, 41, 266-273. [CrossRef]

18. Huang, S.-M.; Kuo, C.-H.; Chen, C.-A.; Liu, Y.-C.; Shieh, C.-J. RSM and ANN modeling-based optimization approach for the development of ultrasound-assisted liposome encapsulation of piceid. Ultrason. Sonochem. 2017, 36, 112-122. [CrossRef] [PubMed]

19. Hu, W.; Guo, T.; Jiang, W.-J.; Dong, G.-L.; Chen, D.-W.; Yang, S.-L.; Li, H.-R. Effects of ultrahigh pressure extraction on yield and antioxidant activity of chlorogenic acid and cynaroside extracted from flower buds of Lonicera japonica. Chin. J. Nat. Med. 2015, 13, 445-453. [CrossRef]

20. Cacace, J.; Mazza, G. Optimization of extraction of anthocyanins from black currants with aqueous ethanol. J. Food Sci. 2003, 68, 240-248. [CrossRef]

21. Yu, H.C.; Tan, F.J. Optimization of ultrasonic-assisted enzymatic hydrolysis conditions for the production of antioxidant hydrolysates from porcine liver by using response surface methodology. Asian-Australas. J. Anim. Sci. 2017, 30, 1612-1619. [CrossRef] [PubMed]

22. Ranjan, D.; Mishra, D.; Hasan, S. Bioadsorption of arsenic: An artificial neural networks and response surface methodological approach. Ind. Eng. Chem. Res. 2011, 50, 9852-9863. [CrossRef]

23. Badkar, D.S.; Pandey, K.S.; Buvanashekaran, G. Development of RSM-and ANN-based models to predict and analyze the effects of process parameters of laser-hardened commercially pure titanium on heat input and tensile strength. Int. J. Adv. Manuf. Technol. 2013, 65, 1319-1338. [CrossRef]

24. Xu, W.-J.; Zhai, J.-W.; Cui, Q.; Liu, J.-Z.; Luo, M.; Fu, Y.-J.; Zu, Y.-G. Ultra-turrax based ultrasound-assisted extraction of five organic acids from honeysuckle (Lonicera japonica Thunb.) and optimization of extraction process. Sep. Purif. Technol. 2016, 166, 73-82. [CrossRef]

25. Pingret, D.; Fabiano-Tixier, A.-S.; Chemat, F. Degradation during application of ultrasound in food processing: A review. Food Control 2013, 31, 593-606. [CrossRef]

26. Hsu, H.F.; Hsiao, P.C.; Kuo, T.C.; Chiang, S.T.; Chen, S.L.; Chiou, S.J.; Ling, X.H.; Liang, M.T.; Cheng, W.Y.; Houng, J.Y. Antioxidant and anti-inflammatory activities of Lonicera japonica Thunb. var. sempervillosa Hayata flower bud extracts prepared by water, ethanol and supercritical fluid extraction techniques. Ind. Crops Prod. 2016, 89, 543-549. [CrossRef]

27. Dennis, J.E., Jr.; Schnabel, R.B. Numerical Methods for Unconstrained Optimization and Nonlinear Equations; Prentice Hall Inc.: Englewood Cliffs, NJ, USA, 1996. 
28. Priyadarshini, R.; Dash, N.; Swarnkar, T.; Misra, R. Functional analysis of artificial neural network for dataset classification. IJCCT 2010, 1, 49-54.

29. Vogl, T.P.; Mangis, J.; Rigler, A.; Zink, W.; Alkon, D. Accelerating the convergence of the back-propagation method. Biol. Cybern. 1988, 59, 257-263. [CrossRef]

Sample Availability: Samples of the compounds did not provide from the authors.

(C) 2019 by the authors. Licensee MDPI, Basel, Switzerland. This article is an open access article distributed under the terms and conditions of the Creative Commons Attribution (CC BY) license (http://creativecommons.org/licenses/by/4.0/). 